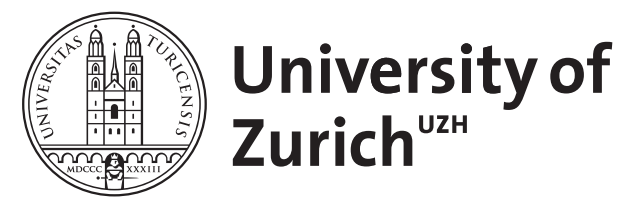

\title{
Economists in the PITS?
}

Frey, Bruno S

\begin{abstract}
Academic economists today are caught in a "Publication Impossibility Theorem System" or PITS. To further their careers, they are required to publish in A-journals, but for the vast majority this is impossible because there are few slots open in such journals. Such academic competition maybe useful to generate hard work, however, there may be serious negative consequences: the wrong output may be produced in an inefficient way, the wrong people may be selected, and losers may react in a harmful way. This paper suggests several ways to remedy this situation.
\end{abstract}

DOI: https://doi.org/10.1007/s12232-009-0081-x

Posted at the Zurich Open Repository and Archive, University of Zurich ZORA URL: https://doi.org/10.5167/uzh-28437

Journal Article

Published Version

Originally published at:

Frey, Bruno S (2009). Economists in the PITS? International Review of Economics, 56(4):335-346.

DOI: https://doi.org/10.1007/s12232-009-0081-x 


\title{
Economists in the PITS?
}

\author{
Bruno S. Frey
}

\begin{abstract}
Academic economists today are caught in a "Publication Impossibility Theorem System" or PITS. In order to further their careers, they are required to publish in A-journals, but for the vast majority this is impossible because there are few slots open for them in such journals. Such academic competition maybe useful to generate hard work; however, there may be serious negative consequences: the wrong output may be produced in an inefficient way, the wrong people may be selected, and losers may react in a harmful way. This article suggests several ways to remedy this situation.
\end{abstract}

Keywords Academia - Economists · Publication · Journals · Incentives · Economic methodology

JEL Classification A1 $\cdot$ D02 $\cdot$ I23

\section{An impossibility}

Many economists feel that they work in the PITS. They are subjected to a publication system, which demands extremely hard work, but offers only a minute chance of success. Today, this applies in particular to young scholars who, in many countries, know that they can only obtain a permanent position at a good university

\footnotetext{
B. S. Frey $(\bowtie)$

Institute for Empirical Research in Economics,

University of Zurich, Winterthurerstr. 30,

8006 Zurich, Switzerland

e-mail: bsfrey@iew.uzh.ch

B. S. Frey

CREMA-Center for Research in Economics,

Management and the Arts, Zurich, Switzerland
} 
if they publish in an "A-journal." ${ }^{1}$ A conventional list of A-journals ${ }^{2}$ includes The American Economic Review, Econometrica, Journal of Political Economy, Quarterly Journal of Economics, and The Review of Economic Studies. Only when a young scholar has had at least one article, preferably two or three, published in these journals, can he or she hope to procure tenure or promotion to a full professorship. A full professor is expected to have articles accepted regularly in these A-journals; otherwise, he or she is considered not up to the task. These "publish in A-journals or perish" requirements are rarely explicit or written down. ${ }^{3}$ That they do, in fact, exist is based on the author's recent conversations with both junior and senior scholars in Austria, Germany, the Netherlands, Portugal, Spain, Sweden, Switzerland, and the United Kingdom. ${ }^{4}$

This article argues that it is simply impossible to meet this requirement because the number of scholars trying to achieve publication in A-journals is far larger than the number of slots open for publication. In order to borrow from a famous theory, one can loosely speak of an "Impossibility Theorem" with respect to publishing requirements: For the population of aspiring academic economists, it is in general impossible to meet publishing requirements. Scholars can thus be taken to work in the PITS, i.e., in a "Publication Impossibility Theorem System".

Table 1 shows the number of slots, or the supply, available in A-journals per year.

Table 1 shows that in 2007 altogether 275 articles were published in A-journals. More than $40 \%$ of those contributions were provided by scholars from the top US universities (Harvard, MIT, Princeton, Yale, Berkeley, and Stanford); more than $80 \%$ of all articles by scholars working in the United States. If this distribution holds in the future (and there is little reason to expect any drastic changes), an academic

\footnotetext{
1 The same holds for business schools in the United States exhibiting an "extreme emphasis" on publications in A-journals (Starbuck 2005). For further evidence, see Moizer (2009).

2 See, e.g., Lee (2006) for various definitions and the corresponding literature.

${ }^{3}$ Faculties of economics at numerous universities (e.g., the University of Linz in Austria), as well as economics associations (e.g., the Verein fuer Socialpolitik, the association of economists in Germany, Austria, and Switzerland), have an official list in which they assign points for publishing in A-, B-, C- etc. journals. Typically, a publication in one of the A-journals listed above gives three times as many points as a B-journal publication. There are also universities that explicitly offer a monetary reward for publishing in highly ranked journals. The University of Economics and Business Administration in Vienna, for example, pays authors 3,000 Euros for publication in what they define as an A+-journal (which, in economics, includes the five journals in the text above, as well as six more), and 1,000 Euros for publication in an A-journal, i.e., a top publication is defined to be worth three times as much as a secondrate one (http://wu-wien.ac.at/forschung.praemie). The Tinbergen Institute in the Netherlands distinguishes between journals ranked "AA", "A," and "B". Among the latter, are (otherwise highly regarded) the reviews such as Economica, Journal of Economic Behavior and Organization, or Economic Letters. Other universities do not consider journal publications lower than A at all. It is sometimes rumored that to publish in B, C, or other lower-ranked journals has even a negative effect on one's career.

4 As always, it is difficult to state whether, and to what extent, this and the following arguments apply to the United States academic system because it is characterized by such a wide variety: The top universities are very different from minor institutions which also call themselves universities. Another question is to what extent the observations and suggestions discussed here also apply to disciplines outside economics. While they can certainly not be directly transferred, there are indications that many aspects are also relevant elsewhere, see, e.g., the discussion by Hewstone and Stroebe (2008) on social psychology.
} 
Table 1 Slots in A-journals, 2007

\begin{tabular}{llcc}
\hline Journal & $\begin{array}{l}\text { Total number } \\
\text { of articles }\end{array}$ & $\begin{array}{l}\text { Articles by scholars } \\
\text { in top US universities }\end{array}$ & $\begin{array}{l}\text { Articles by economists } \\
\text { in the US }\end{array}$ \\
\hline American Economic Review $^{\mathrm{a}}$ & 102 & $44(43 \%)$ & $84(82 \%)$ \\
Econometrica & 51 & $18(35 \%)$ & $38(75 \%)$ \\
Journal of Political Economy & 31 & $19(61 \%)$ & $25(81 \%)$ \\
Quarterly Journal of Economics & 44 & $25(57 \%)$ & $37(84 \%)$ \\
Review of Economic Studies & 47 & $13(28 \%)$ & $40(85 \%)$ \\
& 275 & $119(43 \%)$ & $224(81 \%)$ \\
\hline
\end{tabular}

a Papers and Proceedings are excluded

from any other country (out of the more than 190) in the world can expect to be in the competition for the roughly 50 remaining slots.

It is extremely difficult to estimate how large the demand to publish in top economics journals is in any given year. A rough estimate is that there are around 10,000 academics actively aspiring to publish in A-journals. The true figure is probably even larger, as one single outlet, RePec, lists no less than 20,000 scholars presently creating academic writing. Even if two-thirds of them are from the United States, there are around 7,000 scholars from all other countries. However, it may safely be assumed that a considerable number are not listed in $R e P e c$, precisely because they have not yet been successful in publishing in one of the journals or other publication outlets included in RePec. What matters is that, by necessity, an extremely low share of aspiring scholars will be able to get published in an A-journal. Publication in these journals is characterized by extreme excess demand.

\section{This is just a tournament}

The requirement to publish in A-journals can be understood as a tournament in which only one person or, in our case, a few people can rise to the top, while the great majority of contenders fail to do so (Frank 2001, 2004). Such a tournament (Lazear and Rosen 1981) is held to provide the incentives necessary to put in lots of effort and do better than the other contenders. These are the beneficial effects of "publish or perish" which conventional economics has in mind.

\section{But there may be problems...}

The tournament system reflected in the PITS possibly does not produce the claimed positive overall effects, if the following four problems arise:

\section{If the selection of articles is random or distorted}

The articles accepted in the A-journals must conform exactly to a clearly specified criterion. This criterion is defined within academia, or by the "republic of 
science" (see Polanyi 1967; Merton 1973; Osterloh and Frey 2009a, b), in our case by the peer group of academic economists. Sociologists refer to such a criterion as "self-referential," as it is independent of any outside evaluation. A self-defined criterion could easily be criticized by arguing that any discipline should consider the interests of the wider public. This is particularly true of economics. Many people take it for granted that academic economists should help other people in society, in particular, political and administrative decision makers, to better understand how the economy works and to improve its performance [see, e.g., Colander et al. (2009) addressing the systematic failure of academic economists to adequately deal with the current financial crisis]. While it is difficult to define exactly what this means, it is clear that such an objective is determined from outside the discipline.

Even if the internal criterion by the academic economics profession were consistent with the external criterion described above-which can well be doubted $^{5}$-it remains open to debate whether the members of the discipline are able to select the respective articles. The selection of articles relies on an elaborate system of peer reviews, which is considered the only reliable ex ante evaluation method. However, there exists substantial empirical evidence that in general the peer-review process does not perform very well, and in particular that the selection of articles for A-journals resembles a random process (see, extensively, Daniel 1993; Frey 2003; Bedeian 2006; Weingart 2005; Tsang and Frey 2007; Osterloh and Frey 2009b; Gillies 2008; Raelin 2008). The inter-rater reliability is deficient (see, e.g., Starbuck 2006); the evaluation of an article by various referees, on average, correlates only by $0.2-0.3$, which is also rather low. Moreover, Oswald (2007) recently demonstrated that many articles published in B-journals get far more subsequent citations than many articles published in A-journals. As citations are considered the ultimate ex post evaluation in the profession, this evidence suggests that the present refereeing process is open to criticism.

\section{If the publishing activity is wasteful}

Even if the selection of articles for A-journals were perfect (which it never is nor ever will be), there remains the question whether the social benefits produced by such a publication is worth the input of labor required. This is not necessarily the case, as the hours needed to write an article acceptable for an A-journal can be immense; some scholars work for a year or more to try to get a single article into one of these few journals. Scholars are well aware that a considerable part of this huge effort is devoted to technique and presentation, rather than to content. A large part of the effort is devoted to writing the article such that it will meet the actual or imagined requirements of the referees and editors. ${ }^{6}$ Referring to the high rejection rates, Moizer (2009, p. 1) states a widespread feeling: "Something cannot be right with a system which creates so much apparent waste". A large share of the articles written with huge effort and time input are totally disregarded. The median number

\footnotetext{
5 See the charges of "autism" made against standard economics from many quarters. The movement, which started in the Grandes Ecoles in France and led to an online journal, Post-Autistic Economics Review, is well known.

6 “... academics may spend as much time on the style of their writing and the orientation of their arguments as on the raw content" (Raelin 2008, p. 125; see also Black et al. 1998; Frey 2003).
} 
of citations of economics articles is zero, or close to zero. According to Laband and Tollison (2003), in a sample of 73 journals in 1974 and 91 journals in 1996, 26\% of articles were never cited. One has to go through $70 \%$ of the articles before the average per article has been cited more than once. This can hardly be considered highly productive, as the "dry holes" dominate by far.

It may nevertheless be claimed that even if a vast majority of articles does not make it into an A-journal, and even if the vast majority of publications in A-journals (and elsewhere) were indeed of little or no value (as they are never cited by peers), this production is necessary in order for a few gems to be produced. It is indeed impossible to predict which scientific contributions peers will consider to be important in the future (see, extensively, Osterloh and Frey 2009b). The gems only reveal themselves after some time, often a lengthy period. However, this does not mean that the existing publication process should be taken to be sacrosanct. Different institutional arrangements rather than the existing tournament may be better able to produce the gems, and create less waste. The fact that (especially young) scholars are forced to pursue publishing in A-journals should not be taken to mean that this rule is efficient. It is certainly difficult to undertake even a basic comparison between the social benefits produced by the existing publication activity in A-journals and the huge costs in terms of energy used specifically in trying to get articles published in these journals (see Gans and Shepard 1994). It may be argued that at least the part of the rent-seeking activity devoted to pleasing the referees and the editors, and to fulfill purely formal requirements (such as the ways the citations have to be arranged and the article has to be submitted) is wasteful.

The crucial question is whether a more efficient system is attainable. One should actively consider alternatives to the present arrangement. It should be legitimate to at least ask whether the overall productivity of economists, from the point of view of society, would not be higher if they could choose more freely what and where they wanted to publish (e.g., in the form of books, contributions to collected volumes, and even in the general media), and even whether publishing is the main, or the only, activity in which they should be obliged to engage. It cannot be dismissed readily that economists might perform a more useful social service if a larger number of them were induced to solve pressing and applied current problems rather than to be "wasted" in the useless effort of publishing articles in A-journals.

A more efficient policy than "publish in A-journals or perish" could possibly be to induce scholars to first establish their credentials in economics by writing a number of articles devoted to the solution of concrete issues that, due to their lesser formal elegance, are inappropriate for A-journals.

\section{If the "wrong" people are selected}

A tournament among articles submitted to A-journals only leads to a satisfactory selection of people in academia if writing top articles is the only relevant criterion. This is doubtful as academics have to fulfill various other important activities, i.e., they should be engaged in multiple other tasks. The most important among these are: 
- teaching;

- supporting young scholars (PhDs and postdoctoral students);

- informing and advising the public;

- participating in university administration.

Excelling in these tasks can be, but not necessarily need be, positively correlated with the ability to write A-journal articles. As only peers can evaluate the value of research, there is a permanent danger of an increasing gap between research and practice. Few scholars in economics seem to be ready to seriously consider this dilemma. They prefer to take it for granted that the research published in A-journals is always useful to practice even though there does not seem to be any empirical evidence to support that view (but neither to the contrary, see Frey $2006^{7}$ ).

As the pursuit to publish in top journals is extremely arduous and timeconsuming, it is likely that a negative correlation between publishing and the four tasks just mentioned is generally produced. Because of the time-and-effort constraints, few scholars are able to perform these tasks sufficiently well and also fully engage in the publishing tournament. The publishing record being easy to measure, while the performance with respect to the four other tasks is not, the multiple-task effect (Holmström and Milgrom 1991; Prendergast 1999) suggests that academics mainly engage in publishing efforts and disregard the other tasks.

Imposing strict requirements for publishing in A-journals also tends to lead to an undesirable selection effect among participants, as intrinsically motivated scholars, especially those interested in teaching and informing the public, are likely to be put off while extrinsically motivated scholars thrive (this is the crowding-out effect, see Frey 1997; Bénabou and Tirole 2003). The fact that there are always some extremely gifted and extrinsically motivated scholars who excel in several of these tasks simultaneously is not a sufficient argument to force all of them to participate in the publication tournament. There are not only above average but also below average scholars for whom the requirement to publish in A-journals takes away a very large amount of time and effort from other tasks. Moreover, it is difficult to imagine a well-functioning department composed of A-journal publishing scholars only. A balanced mixture of various capabilities is more likely to work successfully; in particular, it allows the most gifted scholars to have the room to flourish.

\section{If the reaction of the losers is harmful}

The cost of the PITS depends to a great extent on how scholars unable to publish in A-journals react and what their options are. Some people who in the past lost in the tournament keep trying to publish in A-journals but it is unrealistic to assume that they will do so over an extended period. Most of them are realistic enough to realize sooner or later that they will not be successful. They may resort to several kinds of behavior:

\footnotetext{
7 In a related field, accounting, some authors are prepared to conclude that accounting research has little or no effect on practice, see Bedford (1978, p. 2), Dyckman et al. (1978, p. 87), Kaplan (1978, p. 168), Sullivan (1993), and Moizer (2009, p. 3).
} 
(a) They can try to publish in lower-ranked journals knowing that based on that, they will not attain a satisfactory position at a good university. The question is whether such lesser career positions exist in a particular university system. If the strict "publish in A-journals or perish" requirement is in force, such lesser career positions do not exist, and these people, therefore, will have to leave and work outside academia.

(b) The "losers" can decide to give up their plan to stay in the university system and exit the profession. This selection effect is socially beneficial if the publication tournament is fully efficient. Otherwise, the strict requirement to publish in Ajournals leads to an unwanted adverse selection of scholars able to write the necessary A-level articles, but who may turn out to be of little use or even outright failures with respect to other university tasks. The distribution of talent between scholars who are able to publish in A-journals and those who are not is likely to overlap. It follows that the worst scholars with top publications are less able (they are "lemons") than the best scholars without A-level publications. An exit to activities outside the university may be socially beneficial if the effort to publish in A-journals helps them to be better trained in other occupations. This may, but need not, be the case ${ }^{8}$ because the writing of articles for A-journals is a quite specialized activity: a necessary requirement is to follow the self-defined criteria that the economics profession happens to have during a particular period, but which outsiders might not necessarily find important. Today, this refers to the specific way Americans write scientific works, ${ }^{9}$ to the language, and especially to the techniques of analysis used. An example is the current extreme focus on the "identification" problem in econometric analysis, i.e., the need to clearly establish often opposing causal relationships. In many cases, discussions in academic seminars and the decision to reject an article in a journal, are reduced to this issue, essentially neglecting all other, possibly important, aspects. It sometimes seems that the content of a contribution has become more or less irrelevant, and the only thing that really counts is technical dexterity (see Ellison 2002; Frey et al. 2009). An economist sharing this view with the public and wanting to concentrate on issues of content rather than on technique finds it nearly impossible to publish in an A-journal. He or she will then be lost to the profession.

(c) The "losers" stay on as long as they can in their university job (which in some European countries means for very many years, if not for life). They may well be psychologically depressed, even show signs of mental disorder. Others may become aggressive and obstruct the work of those scholars who hope to meet the publication requirements (see Lazear 1995 on sabotage). A milder form of such behavior is taking a long time, and disregarding the time limits set by the editors, when asked to

\footnotetext{
${ }^{8}$ It can be argued that an economist who manages to publish one or two articles in an A-journal is often worse than somebody who engages in broader academic activities, and has published articles in respectable, but not top, journals. The former has devoted all effort to writing articles acceptable to the referees of the top journals, but otherwise is not well trained for the other academic tasks (I owe this point to Reiner Eichenberger).

9 French or German scholars traditionally developed their ideas in a way, which differs fundamentally from the way Americans do today. However, it should not be forgotten that this kind of writing was used by some of the most original and best scholars in the discipline.
} 
referee (thus extending the already long duration journals take for even a first decision) writing dismissive, hostile, or even devastating referee reports for professional journals (Miller 2006). Circumstantial evidence suggests that such negative attitudes have become more common than they used to be in the past, reflecting the increasingly strict publication pressure.

Depending on what type of reaction prevails, the A-journal publication tournament may lead to positive or negative consequences overall. The existing system of forcing scholars to try to publish in top journals only, and disqualifying all other publication outlets, may have negative consequences in various respects.

\section{An open issue}

If the analysis above is correct, then it is debatable whether the PITS is socially beneficial or not. At the least, it should not be taken for granted (as is generally done today) that the PITS is a good, or even the best, way to organize academia. Before such a conclusion is drawn, a serious discussion of the possible negative effects is in order, and much more empirical evidence is needed. The evaluation should not be confined to considering the effects on (internally defined) "scientific excellence," but should also consider the possible negative aspects such as imperfect and biased selection of articles and of scholars, effects on other economic activities and on those scholars not successful in the tournament. Moreover, the present system of the A-journal publication requirement should be compared to alternative ways of organizing science:

(a) One possibility would be to solve the multiple-tasking problem by making an effort to measure all the aspects important for an academic career: teaching, supporting younger scholars, linking up to the public, and participating in academic administration, and so on. While this first option seems straightforward, it is not to be recommended. It would lead to an enormous amount of evaluation, and scholars would invariably find ways to "beat the system".

(b) A quite different, and even contrary, option is to resort to an overall evaluation of young scholars based on the intuitive knowledge of seasoned scholars. There are various possibilities to select such persons. An attractive option would be to elect them by a vote among the members of the respective professional organization. This would ensure that the peers making up the "Republic of Science" are in control. The scholars elected by such a procedure would be under the scrutiny of the profession as a whole and would lose their reputation among their peers if they pushed unfounded personal interests. This gives them an incentive to decide as objectively as possible while maintaining an overall perspective. This option gives the members of professional organizations more power compared to the system prevailing today and helps to fight the oligopolistic tendencies of the small number of A-journals.

Nevertheless, such a procedure seems to be "unscientific" because it is not based on the seemingly neutral measures of publications in A-journals. However, such a view is too simple. According to recent psychological research, "gut feelings" are often superior to in-depth analyses (Gigerenzer 2002, 2007; popularized by 
Gladwell 2005). Indeed, many established scholars proceed in this way when they exchange their views about younger scholars. What matters to them is indeed the gut feeling, and not whether someone has published an article in a particular A-journal.

Using the intuitive knowledge of seasoned scholars has, of course, disadvantages. There is certainly the danger of an "old boys' network" giving young scholars an incentive to attempt to personally please the seasoned scholars. Personality and friendship may matter more than research excellence because gut feelings are to some extent influenced by such perceptions. On the other hand, these claimed disadvantages should not be overrated. It should not be forgotten that the present system focusing on A-journal publications is also influenced by personal relationships and preferences, as well as by selfish interests. It has, for instance, become a common practice in economics to abundantly and positively cite possible referees to raise the chance of acceptance. In contrast, aspiring scholars refrain from criticizing other scholars fearing that they will be chosen as referees and will react negatively. ${ }^{10}$ Even more importantly, scholars in dire need of publication are induced to follow the referees" "advice" even if they clash with their own insights and views. This behavior has been called "academic prostitution" (Frey 2003).

(c) A third possibility is to restrict the PITS to the early phase of a scientific career. Scholars must learn the tools of the trade and must show that they are able to use them with profit. Thereafter, one should let scholars proceed as they see fit for themselves (see more fully Osterloh and Frey 2009b). ${ }^{11}$ This allows them to exhibit their intrinsic motivation in scientific research at least for the remaining part of the career. An obvious disadvantage is that scholars in later phases of their careers are not subjected to any external monitoring and may no longer engage themselves in research. This may well be so but an academic system should be designed to enable the best rather than to prevent the worst. ${ }^{12}$

(d) Yet another possibility would be to more openly shape several levels of scientific careers. In particular, there should be careers at universities and research institutes for which it is sufficient to have published in one or several of the hundreds of other general and specialized journals, but also in the form of books and internet publications, as well as participation in current public debates (i.e., acting as a "public intellectual," see Posner 2002). Such a policy would serve to produce a broader portfolio in the economics profession with respect to type of contribution,

\footnotetext{
${ }^{10}$ Such behavior is, of course, inconsistent with the generally held view of referees solely acting according to professional standards and ethics. It is, however, difficult to see why the economic model of behavior essentially based on self-interest should not apply to scholars in their role as referees.

11 The academic system in some countries works in this way: full professors in particular are not required to show that they continue to publish (or not). To the extent this is the case, the second suggestion has already been realized.

12 It should be kept in mind that no system is able to exclude persons who do not perform well after having entered it. The relevant question is how large their share is, and how badly they affect the system. In the case of academia, the damage is not so large because such people normally decide to engage more in teaching and in administrative tasks. This helps the more productive scholars to have time to do research.
} 
content, techniques and universities. ${ }^{13}$ With the present focus on A-level publications, diversity - a crucial requirement for originality-is indeed threatened as has been empirically shown (see Osterloh and Frey 2009a, b). Requiring each and every scholar to aspire to publish in A-journals is likely to be a flawed focus, and strengthens the oligopolistic power of the five A-level journals whose number and composition has remained constant over an extended period of time. ${ }^{14}$ As in other such factually closed markets, the demanders (i.e., the scholars wanting to publish in such a journal) may to some extent exploit this situation by forcing them to adjust to their preferences and formal requirements. Empirical analysis ${ }^{15}$ suggests that authors from prestigious universities have greater success with A-journals because of their affiliation, but not because they do better research.

Unfortunately, in several European countries (notably in Germany and Switzerland) professors in applied universities (formerly called Fachhochschulen) are now required to engage in advanced research and to publish at the same level and with the same intensity as their colleagues at scientific universities. This expands the prevailing emphasis on top-level publications even further.

Each of these (and possibly other) options has both its advantages and disadvantages, which must be carefully considered in the context of the conditions existing in a particular country at a particular moment in time. In countries where established scholars can attain only limited international importance, the emphasis on publishing in A-journals may turn out to be a preferable strategy. In contrast, in countries where an academic career is more open, less emphasis on A-journal publication records and a more general evaluation by elected seasoned scholars may be more advisable. This article does not propagate any of the options discussed but wants to call attention to the major shortcomings of the present system of "publish in A-journals or perish" to the disregard of other scholarly contributions. We certainly need more empirical evidence on many opinions raised in this article. The major intention is to point out that there are viable alternatives that beg for an open discussion.

Acknowledgments The author is grateful to the reviewers for their helpful comments on earlier versions, and for discussions with Charles Blankart, Hans-Dietrich Daniel, Reiner Eichenberger, Lars Feld, Gerd Gigerenzer, Donald Gillies, Berthold Herrendorf, Bengt Holmström, Todd Kaplan, Alfred Kieser, Gebhard Kirchgaessner, Frederic Lee, Simon Luechinger, Simon Milligan, Peter Moizer, Andrew Oswald, Matteo Rizzolli, Katja Rost, Bill Starbuck, Bodo Steiner, Wolfgang Stroebe, Alois Stutzer, Jean Tirole, and Peter Weingart. The extensive conversations with Margit Osterloh were especially useful. While several of the above persons agreed with me, I wish to state that some of them disagreed, sometimes strongly.

\footnotetext{
13 According to a recent analysis by Oswald (2009) for the United Kingdom, outstanding work-a set of genuinely world-leading articles_-comes from a wide range of sources, namely 21 different universities not normally considered in the top half-dozen in the country.

14 Somewhat surprisingly, as more journals become available online, more recent and fewer journals and articles are cited. Researchers are more quickly put in touch with prevailing opinion tending to accelerate consensus and narrowing the range of ideas and findings (Evans 2008). Alternative procedures to the present publication system are provided by Prüfer and Zetland (2007) and Tsang and Frey (2007).

15 The evidence refers to psychology journals, Peters and Ceci (1982).
} 


\section{References}

Bedeian AG (2006) The manuscript review process: the proper roles of authors, referees, and editors. In: Baruch Y, Sullivan S, Schepmyer H (eds) Winning reviews: a guide for evaluating scholarly writing. Palgrave MacMillan, London, pp 104-116

Bedford NM (1978) The impact of a priori theory and research on accounting practice. In: Abdel-Khalik AR, Keller T (eds) The impact of accounting research on practice and disclosure. Duke University Press, Durham, pp 2-31

Bénabou R, Tirole J (2003) Intrinsic and extrinsic motivation. Rev Econ Stud 70(3):489-520

Black D, Brown S, Day A, Race P (1998) 500 tips for getting published: a guide for educators, researchers and professionals. Taylor \& Francis Group, London

Colander D, Föllmer H, Haas A, Goldberg M, Juselius K, Kirman A, Lux T, Sloth B (2009) The financial crisis and the systematic failure of academic economists. Kiel Working Paper 1489, Kiel Institute for the World Economy

Daniel HD (1993) Guardians of science: fairness and reliability of peer reviews. Wiley, Weinheim

Dyckman TR, Gibbins M, Swieringa RJ (1978) Experimental and survey research in financial accounting: a review and evaluation. In: Abdel-Khalik AR, Keller T (eds) The impact of accounting research on practice and disclosure. Duke University Press, Durham, pp 48-105

Ellison G (2002) Evolving standards for academic publishing: a q-r theory. J Polit Econ 110(5):994-1034

Evans JA (2008) Electronic publication and the narrowing of science and scholarship. Science 321:395399

Frank RH (2001) Higher education: the ultimate winner-take-all market? In: Devlin M, Meyerson J (eds) Exploring the future of higher education, forum futures 2000 papers, Forum Strategy Series, vol 3. Jossey-Bass, San Francisco, pp 2-12

Frank RH (2004) Are arms races in higher education a problem? In: Devlin M (ed) Publications from the Forum for the Future of Higher Education. Forum for the Future of Higher Education, Cambridge, pp 49-42

Frey BS (1997) Not just for the money. Edward Elgar, Cheltenham

Frey BS (2003) Publication as prostitution. Public Choice 116:205-223

Frey BS (2006) How influential is economics? De Economist 154(2):1-17

Frey BS, Eichenberger R, Frey RL (2009) Editorial ruminations: publishing Kyklos. Kyklos 62:151-160

Gans JS, Shepard GB (1994) How are the mighty fallen: rejected classic articles by leading economists. J Econ Perspect 8:165-180

Gigerenzer G (2002) Calculated risk. Simon \& Schuster/Penguin, New York

Gigerenzer G (2007) Gut feelings. Penguin/Viking, New York

Gillies D (2008) How should research be organized? College Publications, London

Gladwell M (2005) Blink. The power of thinking without thinking. Little, Brown and Company, New York

Hewstone M, Stroebe W (2008) Moving at a snail's pace: some observations on the publication process in social psychology. Mimeo, Department of Psychology, University of Utrecht

Holmström B, Milgrom P (1991) Multi-task principal agent analysis: incentive contracts, asset ownership and job design. J Law Econ Organ 7:24-52

Kaplan RS (1978) Information content of financial accounting numbers: a survey of empirical evidence. In: Abdel-Khalik AR, Keller T (eds) The impact of accounting research on practice and disclosure. Duke University Press, Durham, pp 134-173

Laband DN, Tollison RD (2003) Dry holes in economic research. Kyklos 56:161-174

Lazear E (1995) Personnel economics. MIT Press, Cambridge

Lazear E, Rosen S (1981) Rank-order tournaments as optimum labor contracts. J Polit Econ 89(5):841864

Lee FS (2006) The ranking game, class, and scholarship in American mainstream economics. Mimeo, Department of Economics, University of Missouri

Merton RK (1973) Sociology of science: theoretical and empirical investigations. The University of Chicago Press, Chicago

Miller CC (2006) Peer review in the organizational and management sciences: prevalence and effects on reviewer hostility, bias, and dissensus. Acad Manag J 49:425-431

Moizer P (2009) Publishing in accounting journals: a fair game? Acc Organ Soc 34(2):285-304

Osterloh M, Frey BS (2009a) Are more and better indicators the solution? Scand J Manag 25:225-227 
Osterloh M, Frey BS (2009b) The role of incentives for academic research. Integrating to different perspectives. Mimeo, Institute of Organization and Administrative Sciences, University of Zurich

Oswald AJ (2007) An examination of the reliability of prestigious scholarly journals: evidence and implications for decision-makers. Economica 74:21-31

Oswald AJ (2009) World-leading research and its measurement. Warwick economic research papers, no. 887

Peters DP, Ceci SJ (1982) Peer-review practices of psychological journals: the fate of published articles, submitted again. Behav Brain Sci 5:187-255

Polanyi M (1967) Science and reality. Br J Philos Sci 18(3):177-196

Posner RA (2002) Public intellectuals: a study of decline. Harvard University Press, Cambridge

Prendergast C (1999) The provision of incentives in firms. J Econ Lit 37:7-63

Prüfer J, Zetland D (2007) An auction market for journal articles. CentER discussion paper 2007-79

Raelin JA (2008) Refereeing the game of peer review. Acad Manag Learn Educ 7(1):124-129

Starbuck WH (2005) How much better are the most prestigious journals? The statistics of academic publication. Organ Sci 16:180-200

Starbuck WH (2006) The production of knowledge. The challenge of social science research. Oxford University Press, Oxford

Sullivan JB (1993) The impact of auditing research on auditing practice. Audit J Pract Theory 12:1-2

Tsang EWK, Frey BS (2007) The as-is journal review process: let authors own their ideas. Acad Manag Learn Educ 6(1):128-136

Weingart P (2005) Impact of bibliometrics upon the science system: inadvertent consequences. Scientometrics 62:117-131 